\title{
Paisajes rurales: Identificación y caracterización de componentes de paisaje. Parroquia Cotaló. Tungurahua
}

\section{Rural landscapes: Identification and characterization of landscape components. Cotaló Parish. Tungurahua}

\author{
DOI: 10.17981/mod.arq.cuc.28.1.2022.05
}

Artículo. Fecha de Recepción: 15/08/2021. Fecha de Aceptación: 30/11/2021.

\author{
Linda Elizabeth Miranda Paredes \\ Universidad Indoamérica. Quito (Ecuador) \\ elizabethmiranda@indoamerica.edu.ec
Paula Belén Peñaherrera Pachar
Universidad Indoamérica. Quito (Ecuador) paulapenaherrera@indoamerica.edu.ec

\author{
Alexis Nahim Jorgge Patiño \\ Universidad Indoamérica. Quito (Ecuador) \\ alexisjorgge@indoamerica.edu.ec
}

Miranda, L., Peñaherrera, O. y Jorgge, A. (2022). Paisajes rurales: Identificación y caracterización de componentes de paisaje. Parroquia Cotaló. Tungurahua. MODULO

\begin{abstract}
Para citar este artículo: ARQUITECTURA CUC, 28, 157-188, 2022. http://doi.org/10.17981/mod.arq.cuc.28.1.2022.05

\section{Resumen}

Los paisajes rurales en la serranía ecuatoriana guardan rasgos diversos, comunes, singulares. Sin embargo, cada sector tiene su propia identidad y características que los hacen únicos e irrepetibles; en el caso de Cotaló parroquia del cantón Pelileo se encuentran paisajes de extraordinaria belleza y de alto valor escénico, como las cuencas visuales que permiten admirar el volcán Tungurahua. La problemática detectada es el desaprovechamiento de estos recursos en actividades turísticas, recreativas 0 contemplativas, que permitan un desarrollo social sostenible. De hecho, el objetivo es evidenciar el potencial de las áreas naturales. Cabe destacar que, el levantamiento de información del contexto se elaboró con la Metodología de Análisis y tratamiento de paisaje; uso de matrices de caracterización y valoración del territorio, a más de encuestas a la población y entrevistas a autoridades y expertos, En lo esencial, el resultado de la investigación es el reconocimiento e identificación de los diferentes componentes de paisaje: visuales, los biofísicos y los antrópicos. Así mismo, hay que destacar los recursos identitarios tangibles e intangibles. Finalmente, promover el cuidado ambiental, la protección, gestión y ordenamiento del paisaje rural natural. Palabras clave: Valor escénico; caracterización; valoración; protección; gestión y ordenamiento del Paisaje
\end{abstract}

\section{Abstract}

Rural landscapes in the Ecuadorian highlands have diverse, common, unique features. However, each sector has its own identity and characteristics that make them unique and unrepeatable; In the case of Cotaló, a parish of the Pelileo canton, there are landscapes of extraordinary beauty and high scenic value, such as the visual basins that allow you to admire the Tungurahua volcano. The problem detected is the waste of these resources in tourist, recreational or contemplative activities that allow sustainable social development. In fact, the objective is to show the potential of natural areas. It should be noted that the information gathering on the context was prepared with the Landscape Analysis and Treatment Methodology; use of matrices of characterization and valuation of the territory, in addition to surveys of the population and interviews with authorities and experts Essentially, the result of the research is the recognition and identification of the different landscape components: visual, biophysical and the anthropics. Likewise, it is necessary to highlight the tangible and intangible identity resources. Finally, promote environmental care, protection, management and ordering of the natural rural landscape.

Keywords: Scenic value; characterization; valuation; protection; management and ordering of the Landscape 


\section{INTRODUCCIÓN}

De acuerdo con el Convenio Europeo del Paisaje (COE, 2000), "se entiende el paisaje como cualquier parte del territorio, tal como se percibe por las poblaciones, cuyo carácter resulta de la acción de factores naturales y humanos y de sus interacciones" (cap. 1, art. 1, lit. a). De la misma manera, al paisaje también se lo conceptualiza como "percepción polisensorial y subjetiva de la expresión externa en que se manifiesta el sistema territorial" (Gómez, 2010, p. 36), esto implica, que el paisaje está constituido por un componente objetivo, la base paisajística o expresión externa del sistema territorial y el componente subjetivo la percepción de los observadores potenciales (Gómez, 2010).

Es así como el perceptor en su lectura individual del paisaje puede generar diferentes interpretaciones, las cuales dependen de su cultura en particular y su forma de entender el entorno, la población fija de un territorio, visitantes, turistas... se consideran como los perceptores potenciales; desde su óptica pueden alcanzar la objetividad y ser sujetos participativos en los procesos de investigación para determinar los diferentes rasgos, contenidos, vivencias, evocaciones, que hacen de los paisajes únicos e irrepetibles.

Así también, a través del tiempo al paisaje se lo ha representado como un panorama, un majestuoso marco para ilustraciones pictóricas y fotográficas, que en términos menos románticos es la estructura del territorio que agru- pados constituyen las unidades paisajísticas (Martínez, 2009). Cabe destacar que, al paisaje se le atribuyen las siguientes características: Multidimensional por ser dinámico, heterogéneo, multiescalar, cambiante y fractal; integral conformado por la gente y el lugar, cada uno con sus componentes o elementos; complejo en el tratamiento de recursos naturales y la ecología; temporal en la forma de generarse los cambios de manera abiótica, biótica y humana y local por sus características naturales y culturales únicas del contexto.

Fundamentalmente, cada paisaje tiene sus propias dinámicas, la gestión del paisaje lo van configurando y los cambios que se van realizando dependen de su vocación, adquiriendo manifestaciones externas temporales o definitivas, por los usos del suelo; "la gestión de recursos naturales implica una administración del paisaje" (Holden \& Liversedge, 2014, p. 1).

Específicamente, el Ecuador país multi diverso, ubicado en América del Sur, atravesado transversalmente por la línea equinoccial y longitudinalmente por la cadena montañosa de los Andes, además es un país amazónico, con tres regiones geográficas claramente definidas la andina sub andina y la insular de las Galápagos (León, 2014).

De la misma forma, la organización territorial se encuentra políticamente dividida en provincias, cantones y parroquias. La Secretaría Nacional de Planificación del Ecuador (SENPLADES, 2012) afirman lo siguiente: 
Para acercar el estado a toda la ciudadanía a través de la prestación de servicios cálidos y eficientes se requiere una buena planificación en la que participemos todos y todas.

Con este propósito la secretaria nacional de Planificación y Desarrollo, [...] conformó niveles administrativos de planificación: zonas, distritos y circuitos [...]. Las zonas están conformadas por provincias de acuerdo con la proximidad geográfica, cultural y económica, existen 9 zonas administrativas de planificación (p. 5).

Ahora bien, Tungurahua ubicada estratégicamente, en el centro del país, paso obligatorio hacia la región oriental, a la costa y hacia la sierra norte y sur, lo que se ha constituido en una fortaleza para su desarrollo social y económico. En este sentido, según Ospina (2011):

Mientras la mayor parte de las áreas indígenas de la Sierra central ecuatoriana enfrenta un severo deterioro económico y otras áreas relativamente dinámicas viven procesos económicos dependientes de factores externos y aleatorias la región de la provincia de Tungurahua parece destacarse por su presencia de varias actividades económicas moderadamente exitosas ligadas a una particular historia local (p. 48).

En efecto, la provincia de Tungurahua de acuerdo con el Plan de Desarrollo en el Ecuador, forma parte de la zona 3 junto con las zonas Cotopaxi, Pastaza y Chimborazo. Es considerada el centro del país y una zona estratégica de paso entre la Costa, la Sierra Interandina y la Amazonía. Consta de los cantones, Ambato su capital, Pelileo Mocha, Quero, Píllaro, Patate y Baños; el cantón San Pedro de Pelileo, se ubica en el centro de la provincia de Tungurahua, y debido a la producción agropecuaria, manufactura y dinámica comercial, se ha constituido en un centro de acopio y de comercialización a nivel nacional. Además, Pelileo consta de ocho parroquias rurales: García Moreno, Cotaló, Huambalo, Salasaca El Rosario, Bolívar y Chiquicha; y dos urbanas, La Matriz y Pelileo Grande.

Ahora bien, los resultados de los estudios del Plan de Desarrollo y Ordenamiento TerritorialPDOT de la Parroquia rural Cotaló (2015):

Cotaló forma parte de las parroquias rurales del cantón Pelileo provincia de Tungurahua, se ubica al sur del cantón a una altura aproximada de 2500 m.s.n.m. a 10 km del cantón Pelileo, cuenta con una superficie de $43.9 \mathrm{~km}^{2}$ que representa el 3\% de la superficie total cantonal (p. 1).

En todo caso, la parroquia rural se distribuye en nueve asentamientos, incluyendo el centro urbano; la comunidad con mayor extensión es Cusúa, sin embargo no es la más habitada debido al riesgo al que se encuentra expuesta por su cercanía al volcán Tungurahua.

TABla 1.

Proyección de habitantes según áreas en la parroquia Cotaló año 2020.

\begin{tabular}{lll}
\hline \multicolumn{1}{c}{ Áreas } & \multicolumn{1}{c}{ Población } & \multicolumn{1}{c}{$\%$} \\
\hline Área rural & 1801 & 82.34 \\
Cabecera parroquial & 387 & 17.66 \\
Total & 2188 & 100 \\
\hline
\end{tabular}

Fuente: Adaptado de la Parroquia Rural Cotaló (2015). 
Por esta razón, en el caso de los paisajes del cantón Cotaló funcionalmente son eminentemente agrícolas y ganaderos, además se han sumado la proliferación de planteles avícolas calificándole de gran productor de huevos. Sin embargo, es importante realizar un levantamiento de información para identificar y caracterizar los paisajes, generar un registro de las potenciales que promuevan nuevas actividades y formar prácticas sostenibles de cuidado a las áreas naturales.

De hecho, el análisis y el tratamiento de paisaje, se lo puede trabajar en las siguientes escalas: A escala territorial, a escala urbana y a pequeña escala, cuyas actuaciones se van insertando en los Planes de Ordenamiento y Planificación Territorial, a diferentes niveles de gobierno, con competencias otorgadas por la Constitución del Ecuador (Cordero, 2014).

Cabe destacar que, en este caso el tratamiento del nivel parroquial debe se lo realiza en coordinación con los anteriores niveles. De igual manera, la percepción de los habitantes son importantes como "por medio de su paisaje permite construir una serie de imágenes que resaltan rasgos, hitos y particularidades de mayor reconocimiento e identidad" (Wiesner, Puerto, Galindo, Arriaga y Salazar, 2019). Si bien es cierto, una de las características del paisaje es integral para el estudio de este paisaje singular, se determinó los componentes visuales, biofísicos y visuales con sus diferentes elementos. Cabe recalcar que, la población de los sectores rurales conoce su territorio, identifican y reconocen sus características por ser parte de sus actividades cotidianas y vidas.
Eso quiere expresar, la estrecha relación de la población rural con su terruño, senderos, chaquiñanes, fauna y flora; demandan de mecanismos que permitan disfrutar de estos espacios de integración comunitaria y ayudar al fomento de turismo generando una nueva fuente de ingresos y progreso. "El paisaje constituye una importante motivación para los visitantes, tanto turistas como excursionistas, llegando en algunos casos a ser la motivación más relevante para la elección del destino" (Santos-Tabales, Fernández-Pavó y MuñozYules, 2016, p. 175).

Continuando, los recursos de la parroquia se los puede catalogar en tres grupos: los visuales, la textura como la expresión externa del tejido parcelario, la variedad de cultivos y el potencial de vistas; los biofísicos, con sus fortalezas ecológicas, el agua de las vertientes naturales, laguna y humedal; y los antrópicos con los asentamientos poblacionales, equipamientos existentes y vías de comunicación.

Así mismo, hay que destacar los recursos identitarios tangibles e intangibles. Además, es importante señalar que, al hablar de los paisajes rurales implícitamente se entiende del paisaje cultural como lo afirma Yarham (2011):

Los paisajes rurales poseen contenidos culturales con significado en la misma identidad regional, como referencial de sus sentidos geográficos e históricos de las que surgió la comarcalización tradicional, que definió las unidades básicas del territorio y constituyó las señas de identidad del país (p. 54). 


\section{Metodología}

La metodología utilizada en el presente estudio es la metodología de análisis y tratamiento del paisaje, es una metodología cualitativa y cuantitativa, con en cumplimiento de las siguientes fases: Identificación y caracterización; y Valoración y evaluación.

Es así como, en la fase de Identificación y caracterización se determinaron las principales características del territorio y componentes del paisaje en base al levantamiento documental y fotográfico de territorio, cabe mencionar que en el trabajo de campo es importante contar con las bases cartográficas, información sobre la denominación de los paisajes. En la siguiente fase se realizaron matrices de valoración desde los puntos más significativos a nivel social, cultural y natural del territorio; y por último la fase de evaluación.

De allí la importancia de determinar los componentes del paisaje a analizar los cuales se sintetizan en los tres grupos mencionados. Esta clasificación no es rígida y pueden presentarse otras formas:

- Elementos Biofísicos: Geomorfología, exposición, pendiente, existencia de láminas de agua, fauna y vegetación, clima, sonido y ruidos. Estos tres últimos elementos no son permanentes, $y$ tienen un carácter temporal o efímero.

- Elementos Visuales: Extensión de la cuenca visual; forma de la cuenca visual: compacidad, altura relativa, coeficiente de forma, planos de visión; características: escala, contraste, dominancia, compatibilidad (forma, línea, color, textura, armonía, variedad).
- Elementos Antrópicos: Accesibilidad, vías de comunicación, elementos singulares, elementos culturales, elementos históricos, elementos arquitectónicos.

De modo similar, Nogué y Sala (2008) utilizan la metodología de tratamiento de Paisaje para la construcción de catálogos y desglosa el alcance de las fases: "Identificación y caracterización del paisaje. Evaluación del paisaje. Definición de los objetivos de calidad paisajística. Establecimiento de directrices, medidas y propuestas de actuación” (Nogué y Sala, 2008, p. 85).

Por ello, el autor con respecto a la fase de evaluación menciona:

Evaluación del paisaje consiste en estudiar las amenazas, las debilidades, las fortalezas y las oportunidades para la protección, gestión y ordenación del paisaje, en clave de sostenibilidad, para cada unidad y paisaje de especial atención. Es importante en este punto analizar las respuestas de la administración y de las entidades, es decir los cambios de políticas públicas o de actitudes individuales o colectivas para disminuir la presión sobre el paisaje y mejorar su calidad (Nogué y Sala, 2008, p. 92).

De igual forma, la investigación es cualitativa porque se realizaron entrevistas a profesionales para obtener una apreciación objetiva de la realidad paisajística, territorial y social de la parroquia. Sin embargo, los resultados arrojados de la aplicación de los antes mencionados instrumentos de investigación denotaron una gran similitud o discordancia entre ellos, lo cual sesga la información. 
De todos modos, se decidió aplicar el procedimiento metodológico de triangulación, con la finalidad de articular y validar los datos que se centran en un mismo problema. Según Rodríguez, Pozo y Gutiérrez (2006), "dicha triangulación está referida a la confrontación de diferentes fuentes de datos en un estudio", sin importar su tipología.

Dicho esto, en respuesta al proceso de confrontación de los datos seleccionados por su nivel de relevancia y apoyo a la hipótesis, se obtienen conclusiones que reflejan resultados coherentes; las cuales se resumen correspondientemente en tres: paisaje, flujos y usuario.

\section{Revisión Literaria}

La belleza del paisaje interandino ecuatoriano y particularmente el de la provincia de Tungurahua nos invita a realizar recorridos, en cuyo desarrollo se encuentran amplias cuencas visuales, llenas de colorido, variada flora y fauna, un perfil montañoso tan rico en elevaciones, volcanes, depresiones, quebradas, aún se alcanza a percibir escenarios naturales tan variados (Miranda, 2017, p. 51).

Según el PDOT de la Parroquia Rural Cotaló (2015) cada habitante cuenta con $4.8 \mathrm{~m}^{2}$ de área verde; sin embargo, conforme con lo estipulado por la Oganización Mundial de la Salud en 2016 cada habitante debe contar con un área verde de $9 \mathrm{~m}^{2}$. Dicho esto, existe un déficit de $4.2 \mathrm{~m}^{2}$ por habitante, realidad que refuerza sobre la necesidad de diseñar proyectos paisajísticos con la finalidad de aportar al índice verde de la parroquia. Además de la contribución de zonas de esparcimiento y recreación que en la actualidad son muy escazas.

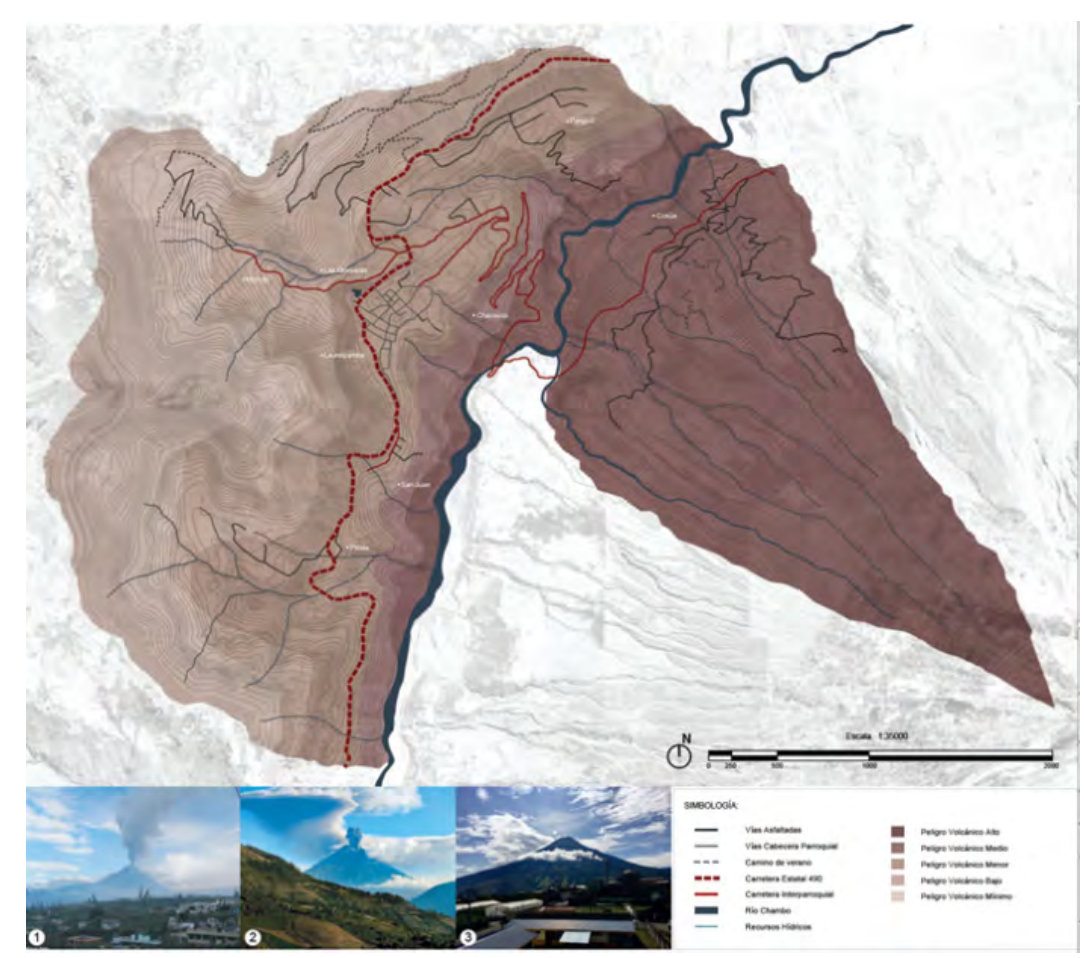

Figura 1. Mapa de riesgo volcánico.

Nota: Adaptado de Parroquía rural Cotaló (2015).

La importancia del análisis a nivel parroquial recae en la obtención de información relacionada a morfología, riesgos, uso de suelo, ecosistemas, recursos, jerarquía vial y demás. Obteniendo como producto su ubicación exacta y ordenada en mapas; lo cual familiariza al investigador con el territorio para su posterior elección de las posibles zonas de implantación para el centro turístico. Es por ello, que se realiza secuencialmente una serie de mapas adaptados a lo establecido previamente en el Plan de Desarrollo y Ordenamiento Territorial de la parroquia en cuestión. 
En tal virtud, se concluye que la parroquia rural además de caracterizarse por su producción avícola, agrícola y ganadera, que son la mayor y única fuente de ingresos económicos para sus habitantes. Sin embargo, el PDOT considera que es preciso implementar proyectos enfocados a actividades turísticas para así percibir otros ingresos, crear ofertas de empleo y así dinamizar la economía local.

Por otra parte, el relieve de la parroquia es accidentado por la presencia de montañas, ríos y el volcán Tungurahua, este último a pesar de su cercanía no representa un riesgo para la mayor parte de los asentamientos, únicamente para Cusúa quienes tienen establecidos un plan de evacuación en caso de erupción volcánica. "A través del análisis fotográfico, podemos obtener una lectura que nos ayuda a comprender la complejidad del espacio geográfico" (Alagna, 2013).

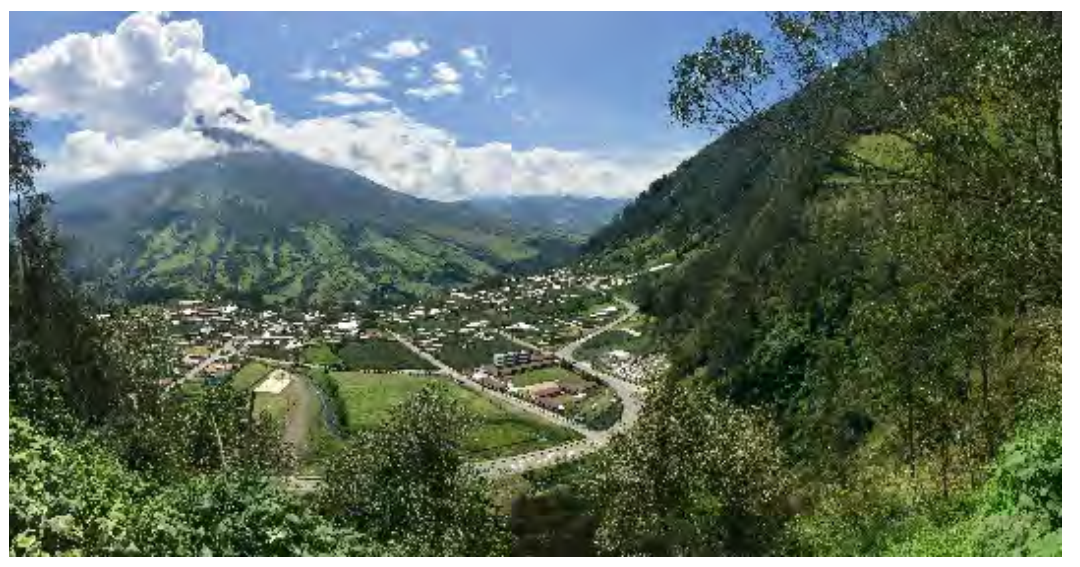

Figura 2. Vista panorámica de Cotaló.

Nota: Fotografía tomada por el equipo de investigación.
De la misma manera, con respecto a los ecosistemas, la parroquia goza de una gran variedad de flora y fauna, la presencia recursos hídricos y la altura del relieve ha dado partida a que ciertos ecosistemas tengan lugar, dicho esto es común observar humedales, cascadas, cerros y quebradas.

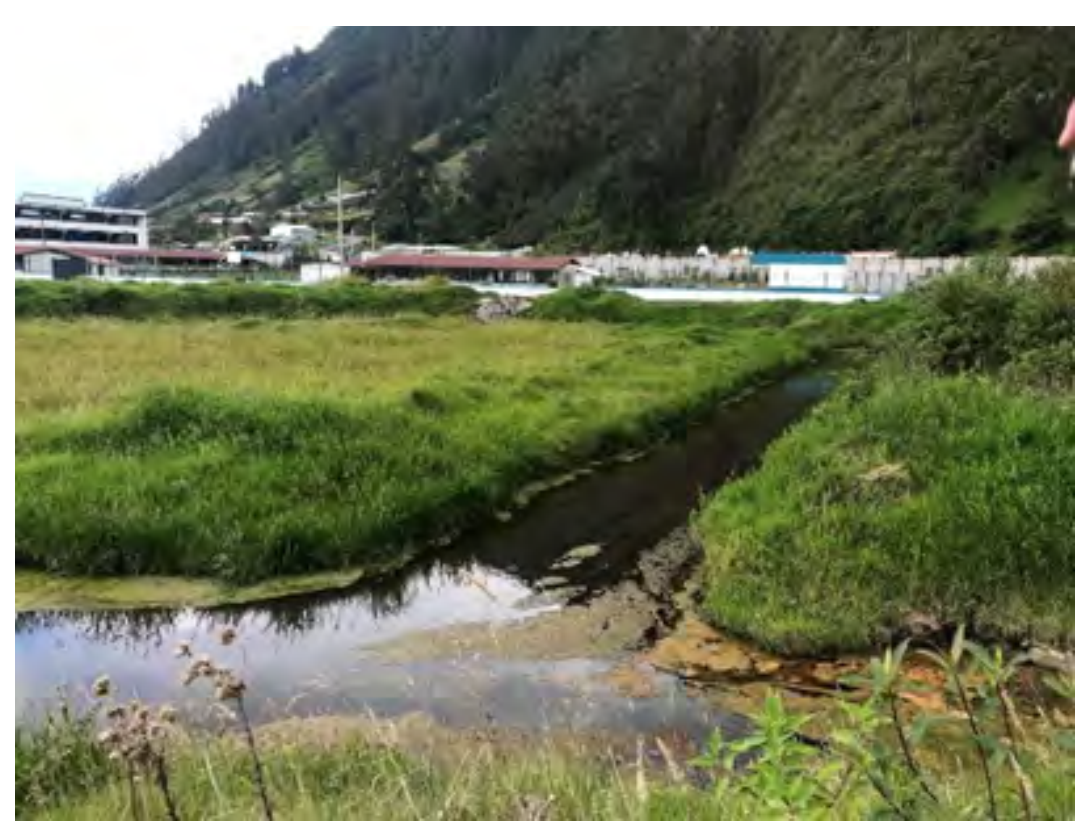

Figura 3. Vista del Humedal "La Cocha".

Nota: Fotografía tomada por el equipo de investigación.

Es importante destacar que ciertas áreas en el páramo son consideradas bosques protegidos. "La planificación turística enfocada en el desarrollo debe estar atenta a necesidades globales de la sociedad, organizando las relaciones entre el ambiente natural y tecnológico entre los intereses colectivos e individuales que afectan y son afectados por las intervenciones" (Abrahão \& Gandara, 2014). 


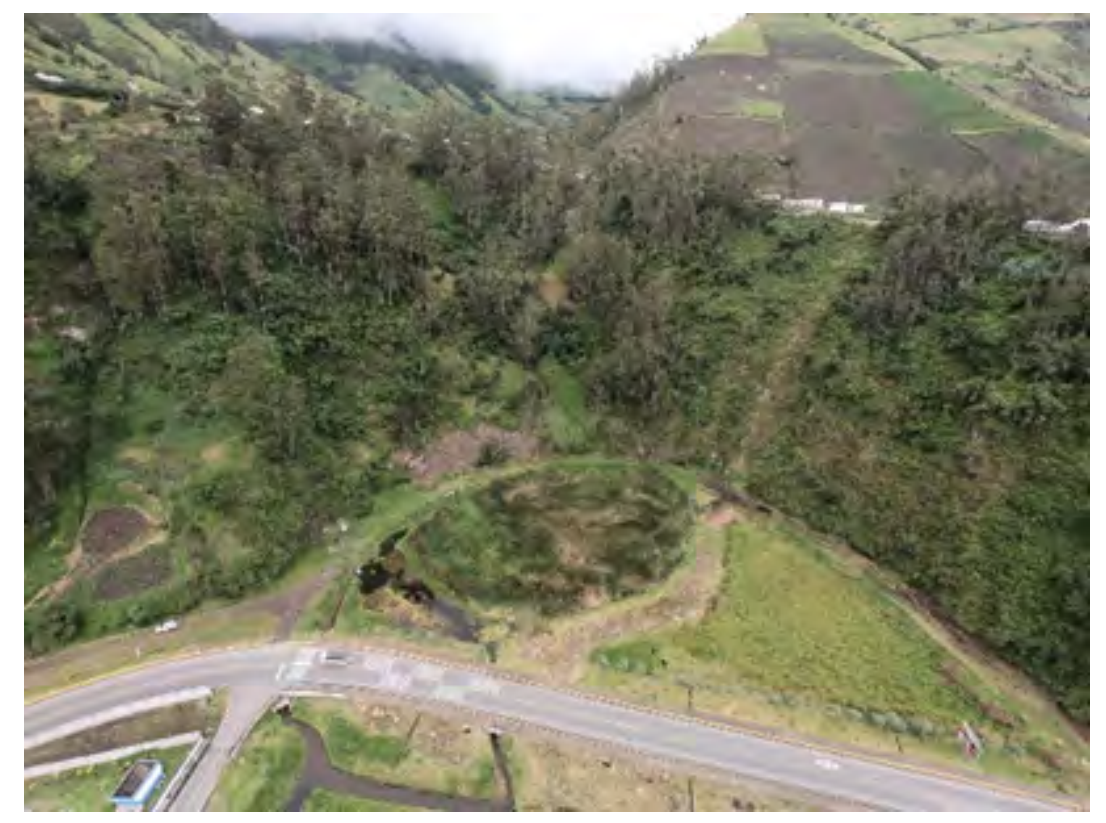

Figura 4. Fotografía de la Vista panorámica de Cotaló.

Nota: Fotografía tomada por el equipo de investigación.

\section{Resultados}

A fin de que, el objetivo de la presente investigación se cumpla, se fijaron seis puntos relevantes dentro de la parroquia, en los mismos que se analizan los diferentes componentes, las condiciones de los elementos biofísicos (geomorfología, exposición, recursos hídricos, flora, fauna); antrópicos (accesibilidad, vías de comunicación, elementos singulares, culturales, arquitectónicos); que se constituyen en indicadores de evaluación donde se exponen sus características, sus ventajas y sus desventajas del territorio de estudio. Este análisis se determinó con la construcción de las tablas de valoración paisajística. en donde se evidencia la gran riqueza de los recursos naturales, culturales e históricos de Poaló para promover la protección a través del desarrollo turístico gracias a sus características físico-espaciales y que se encuentran establecidos en el PDOT de la Parroquia Rural Cotaló (2015).

Con respecto a los elementos biofísicos: La exposición que corresponde a los índices de iluminación son altos alcanzando un $95 \%$; las pendientes que se encuentran oscilan entre cuatro niveles: del 0 al 5\% en la cabecera parroquial con usos residenciales; agrícola e industrial; del 5\% - 12\% de uso agropecuario; $12 \%-25 \%$, de uso agropecuario; $25 \%$ - $50 \%$ se encuentran quebradas, y en el $70 \%$ de pendiente, presencia de bosques y sobre estos niveles páramos y laderas designadas como áreas protegidas.

Con relación a láminas y cuerpos de agua la parroquia, en la parroquia se hallan la cuenca del río Pastaza, y la microcuenca del río Chambo. En el centro parroquial, pasando la carretera Estatal 490, está el humedal La Cocha, área protegida con una superficie de $123891 \mathrm{~m}^{2}$. El clima tiene una temperatura que oscila de $8^{\circ} \mathrm{C}$ a $18^{\circ} \mathrm{C}$, de promedio $15^{\circ} \mathrm{C}$.

Así también, la formación de la corriente de agua en la cúspide de la montaña a través de procesos naturales de condensación y del tiempo forjaron "El Humedal", constituyéndose en el recurso identitario tangible y cuya protección es el objetivo de la población.

A fin de que se precautele la conservación del recurso agua se promueve la libre trayectoria hídrica, sumados al aprovechamiento de todos 
los recursos de manera sustentable en las áreas verdes, cuidado y protección de especies propias del lugar, entre las que se destaca la polylepis o árbol de papel debido a que es una especie en peligro de extinción, de la misma forma el respeto de las zonas donde habitan la fauna como las electoris rupa (gallinas de páramo) con restringida y limitada la actividad humana.

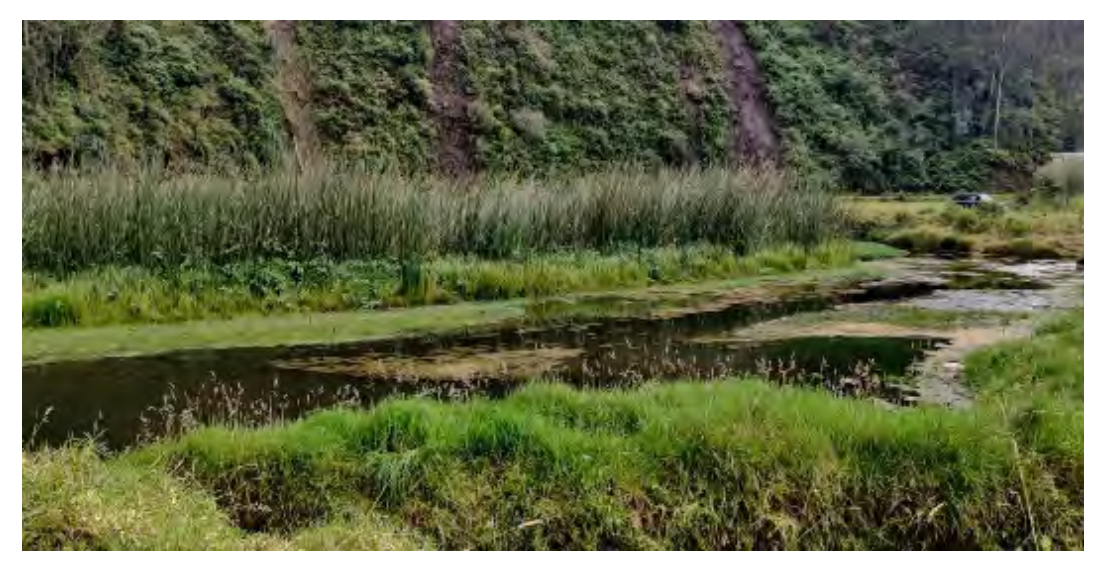

Figura 5. Vista panorámica del Humedal.

Nota: Fotografía tomada por el equipo de investigación.

Ahora bien, sobre la flora y la fauna esta caracterizado por parcelas con cobertura natural de diferentes tipos, además cultivos comestibles de ciclo corto, bosque natural y plantado, pasto natural y plantado, vegetación natural, arbustos.

El humedal, considerado como el escenario principal se caracteriza por su forma ovalada y abarca una extensión considerable del territorio, es alimentado por vertientes naturales lo que favorece a que exista una circulación continua de agua. Dentro del ecosistema cumple un papel fundamental en su mantenimiento, en él habitan ciertas especies herbáceas y arbustivas, una de ellas la oreopanax ecuadorensis, las cuales en pequeños grupos se han visto atacadas por especies introducidas debido a la fragilidad de sus ecosistemas. Es importante resaltar que cerca del humedal existe un área donde habitan electoris rupa (gallinas de páramo), especies propias de la parroquia.

De la misma manera, se determinó que la isla de scirpus totora ubicada en la parte central del humedal, fue creciendo exponencialmente debido a que se trata de una especie herbácea acuática de carácter resistente, que lamentablemente podría llegar a ocupar toda la superficie del cauce hídrico lo cual dificultaría su continua circulación. En adición, se registran diferentes especies, algunas de ellas sembradas por los mismos habitantes como populus alba, las cuales se ubican a lo largo del perímetro vial.

La montaña, ubicada al oeste se caracteriza por su carácter silvestre, grupos de grandes especies de eucaliptus se esparcen a lo largo de este territorio, en ciertas zonas a altas densidades y en otras mantienen una distancia entre ellos. Por otra parte, desde la parte superior de la montaña se puede apreciar toda la extensión del caserío y al fondo la majestuosa presencia del volcán Tungurahua.

En lo que respecta a lo antrópico, a lo largo de los años el territorio "La Cocha" ha sido expuesto a cambios en su morfología relacionados con la intervención del hombre. El primero de ellos, la 
construcción de la carretera estatal 49 provocó la segmentación del humedal, es por ello por lo que el agua proveniente del humedal y que alimenta los cauces hídricos que se forman en la zona este aledaño a la vía, se encuentra soterrada. En ocasiones el nivel de agua llega a ser alto, razón por la cual el agua que alimenta todo este sistema hídrico debe ser controlada.

Adicionalmente, en la zona este del territorio se ubican ciertos elementos arquitectónicos tales como: canchas deportivas y una zona con juegos infantiles; es importante mencionar que uno de los terrenos ha sido nivelado.

En efecto, la actividad turística "puede convertirse en una forma integradora del proceso de desarrollo y crecimiento de una localidad o de un país, usando las increíbles capacidades de diversificación económica y manejo sostenible de los recursos existentes" (Bacci \& Mujica, 2001).

Cabe destacar que "la planificación turística enfocada en el desarrollo debe estar atenta a necesidades globales de la sociedad, organizando las relaciones entre el ambiente natural y tecnológico entre los intereses colectivos e individuales que afectan y son afectados por las intervenciones" (Abrahão \& Gandara, 2014).

Dentro de los elementos singulares, la conexión habitual que existe desde lo alto de la montaña, hacia el humedal "La Cocha" por medio de senderos de tierra que se configuran en sitios de encuentro y comunicación, actividad propia de los lugareños y práctica que fortalece el patrimonio cultural y las costumbres.

\section{Conclusiones}

En todo caso, en la fase de identificación y caracterización del paisaje, al observar las fotografías se perciben los diferentes sectores que configuran tres escenarios: la montaña, el humedal y lo antrópico.

Como consecuencia, se establecen los siguientes puntos de extraordinaria belleza a lo largo del territorio:

\section{Mirador caserío Panguilí.}

2. Cerro Tungurahuilla.

3. Humedal "La Cocha".

4. Cerro Mul-Mul.

\section{Cascadas de Sto. Domingo.}

Se puede señalar que, la importancia paisajista recae en los elementos singulares que se ubican en el territorio tales como el humedal y la montaña; su conveniente ubicación aporta a una visión panorámica del volcán Tungurahua, el mismo que actúa como atractivo turístico esencial. Sin duda, el valor paisajista que posee el humedal "La Cocha", el sentimiento de apropiación por parte de sus habitantes fortalece su valor social e histórico, por la estrecha relación de respeto y cuidado hacia el recurso agua, razón por la cual se mantiene actualmente en buenas condiciones; es así como, este recurso integrado al diseño de paisaje ayudará a conciliar objetivos de desarrollo turístico y sostenibilidad ambiental.

Además, se determinan las siguientes conclusiones: 
- Limitada existencia de espacios y equipamientos que cuenten con las condiciones físico-espaciales para desarrollar actividades destinadas al turismo ecológico y al disfrute de los recursos naturales en la parroquia Cotaló se hace necesario realizar intervenciones que promuevan el respeto y protección del medio natural.

- Diversidad de componentes de paisaje evidenciados en las tablas de valoración lo catalogan como una parroquia rural con una riqueza de recursos naturales, culturales e históricos.

- Las actividades agrícolas, avícolas y ganaderas de la población rural la posicionan como un destino turístico. Por lo cual, se valorizan dos flujos de personas con el objetivo de ser considerados como virtuales usuarios: el primero, proveniente desde Pelileo, debido a la comercialización de jeans; por otra parte, un segundo flujo hace referencia al porcentaje de usuarios de la carretera E490 Baños-Penipe, en promedio 500 vehículos diarios con proyección a aumentar en fechas de feriado (San Pedro de Pelileo, 2015). A pesar de que Cotaló actualmente no sea considerado un destino turístico se valorizan estos flujos importantes, para generar diversificación y dinamismo económico local.

- El planteamiento de soluciones sostenibles para la conservación y apropiación del territorio además garantizar las relaciones entre el medio ambiente y la Arquitectura del paisaje con intervenciones que ayuden a preservar estos lugares con políticas que los resguarden, adoptando materiales de ciclo cerrada y sistemas constructivos amigables con el entorno.
- Cualquier intervención en un medio natural afecta directamente tanto a la sociedad como a su ecosistema, es por esto, que la planificación y el ordenamiento territorial se enfoca en el desarrollo, con estrategias direccionadas al cumplimiento de los principios de protección, ordenamiento y gestión del paisaje.

- Finalmente se determina que tanto la economía como la producción local se dinamizaría a través de estrategias paisajísticas implementadas en lugares especiales como "La Cocha" por su configuración geomorfológica, las láminas de agua en el humedal, el potencial de vistas además, los dos tipos de usuario: el turista, para quienes se deberá pensar en actividades que diversifiquen sus opciones, de tal manera garantizar su estancia; y el habitante, este último muy importante debido a que será quien ejerza un rol de permanencia continua por lo tanto de empoderamiento.

\section{REFERENCIAS}

Abrahão, C. y Gandara, J. M. (2014). Reflexiones sobre el desarrollo y turismo en procesos de intervención en waterfronts: Los casos de las ciudades brasileñas Recife y Río de Janeiro. Estudios y Perspectivas en Turismo, 23(2), 207-232. Recuperado de https://www. estudiosenturismo.com.ar/PDF/V23/N02/ v23n2a01.pdf

Alagna, M. (2013). Infiltraciones. Regenerando el Ecosistema. [Projecte Final de Màster Oficial]. Universidad Politécnica de Cataluña, Barcelona. Disponible en http://hdl.handle. net/2099.1/18925 
Bacci, M. E. y Mujica, E. (2001). Turismo rural en el Angel, Carchi, Ecuador: Perspectivas y posibilidades. [Informe]. Quito: Condesan. Disponible en http://www.asocam.org/node/52297

Consejo de Europa. (20 de octubre de 2000). Convenio europeo del paisaje. [COE]. BOE: 31. Disponible en https://www.mapa.gob. es/es/desarrollo-rural/planes-y-estrategias/ desarrollo-territorial/convenio.aspx

Cordero, F. (2014). Competencias y Gestión Territorial: Memorias del VIII simposio Nacional de Desarrollo urbano y planificación territorial. Cuenca: Austrocopy. Disponible en http://sndu.org/archivos/memorias/

Gómez , D. (2010). El Paisaje como recurso: desarrollo de un modelo para su análisis, diagnóstico y planificación. Revista de la Escuela de ciencias Geograficas (GEOPUCE), 35-44. Disponible en https://oa.upm.es/10931/

Holden, R. \& Liversedge, J. (2014). Arquitectura del paisaje: Una introducción. Barcelona: Blume.

León, J. (2014). Geografía del Ecuador. Medio natural, población y organización del espacio. Quito: Corporación Editora Nacional-UASBE.

Martínez, E. (2009). Miradas sobre el Paisaje. Madrid: Biblioteca Nueva.

Miranda, L. E. (2017). Diseño del parque ecológico lineal- recreacional "El Censo" del cantón Tisaleo, provincia de Tungurahua. [Tesis maestría]. Universidad de Cuenca, Cuenca. Disponible en http://dspace.ucuenca.edu.ec/ handle/123456789/27754
Nogué, J. y Sala, P. (2008). El paisaje en el ordenamiento del territorio. Los catálogos del paisaje de Cataluña. Cuadernos geográficos, 43(2), 69-98. Disponible en https://revistaseug.ugr. es/index.php/cuadgeo/article/view/1110

Ospina, P. (Coord.) (2011). El territorio de senderos que se bifurcan. Tungurahua: economia, sociedad y desarrolo. Quito: Corporación Editorial Nacional.

Parroquía rural Cotaló. (2015). Plan de Desarrollo y Ordenamiento Territorial de la parroquia rural Cotaló —Diagnóstico-. Quito: Digipredios. Recuperado de http://app.sni.gob.ec/ sni-link/sni/PORTAL_SNI/data_sigad_plus/ sigadplusdiagnostico/1865014890001_GADP_ COTALO_PDyOT_FASE_DIAGNOSTICO_14-08-2015_15-03-33.pdf

Peñaherrera, P. (2020). Diseño paisajístico de un centro tirístico en la parroquia rural Cotaló del cantón Pelileo. [Tesis de Pregrado]. Ambato: Universidad Tecnológica Indoamérica. Disponible en http://repositorio.uti.edu.ec//handle/123456789/2067

Rodríguez, C., Pozo, T. y Gutiérrez, J. (2006). La triangulación analítica como recurso para la validación de estudios de encuesta recurrentes e investigaciones de réplica en Educación Superior. Relieve, 12(2), 289-305. https://oi. org/10.7203/relieve.12.2.4231

San Pedro de Pelileo. (2015). Actualizacion delplan de desarrollo y ordenamiento territorial del canton San Pedro de Pelileo 2014-2019. Pelileo: Alcaldía de Pelileo. Recuperado de http://app.sni.gob.ec/ sni-link/sni/PORTAL_SNI/data_sigad_plus/ sigadplusdocumentofinal/1860000640001_ACTUALPDYOT2015_15-03-2015_21-58-23.pdf 
Santos-Tabales, E., Fernández-Pavón, A. y MuñozYules, O. (2016). La incorporación del paisaje a la planificación turística. Análisis de la estrategia de turismo sostenible de Andalucía. Cuadernos de Turismo, (37), 497-502. https:// doi.org/10.6018/turismo.37.256201

SENPLADES. (2012). Proceso de desconcentración del Ejecutivo en los niveles administrativos de planificación. [Folleto Informativo]. Quito: SENPLADES. Disponible en www. planificación.gob.ec

Wiesner, D., Puerto, A., Galindo, M., Arriaga, D. y Salazar, D. (2019). Paisajes ciudadanosde Bogotá. El territorio percibido a través de la experiencia cotidiana. Dearq, (24), 68-77. https://doi.org/10.18389/dearq24.2019.06

Yarham, R. (2011). Como Leer Paisajes. Madrid: Akal.
Linda Elizabeth Miranda Paredes es Magister en Arquitectura del Paisaje. Magister en Docencia y Currículo para la Educación Superior. Arquitecta Urbanista de la Universidad Indoamérica (Ecuador). https://orcid.org/00000002-5143-6248

Paula Belén Peñaherrera Pachar. Universidad Indoamérica (Ecuador).

Alexis Nahim Jorgge Patiño. Universidad Indoamérica (Ecuador). 


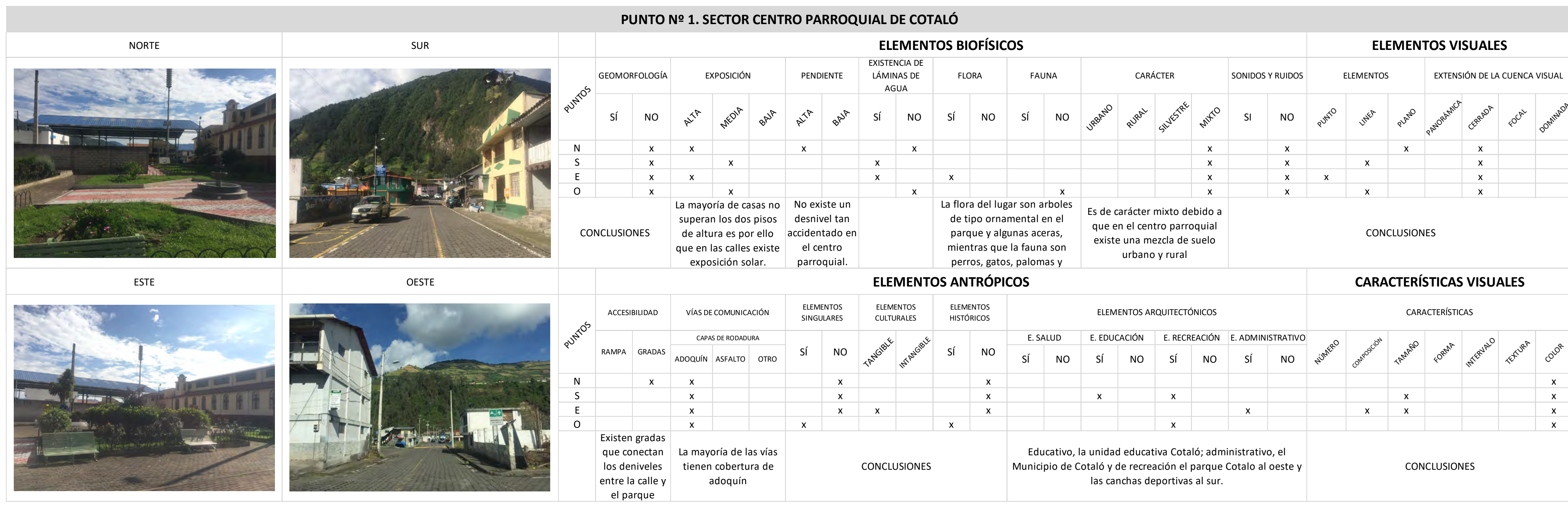

Anexo 1. Punto 1. Sector Centro de la parroquia Cotaló. 


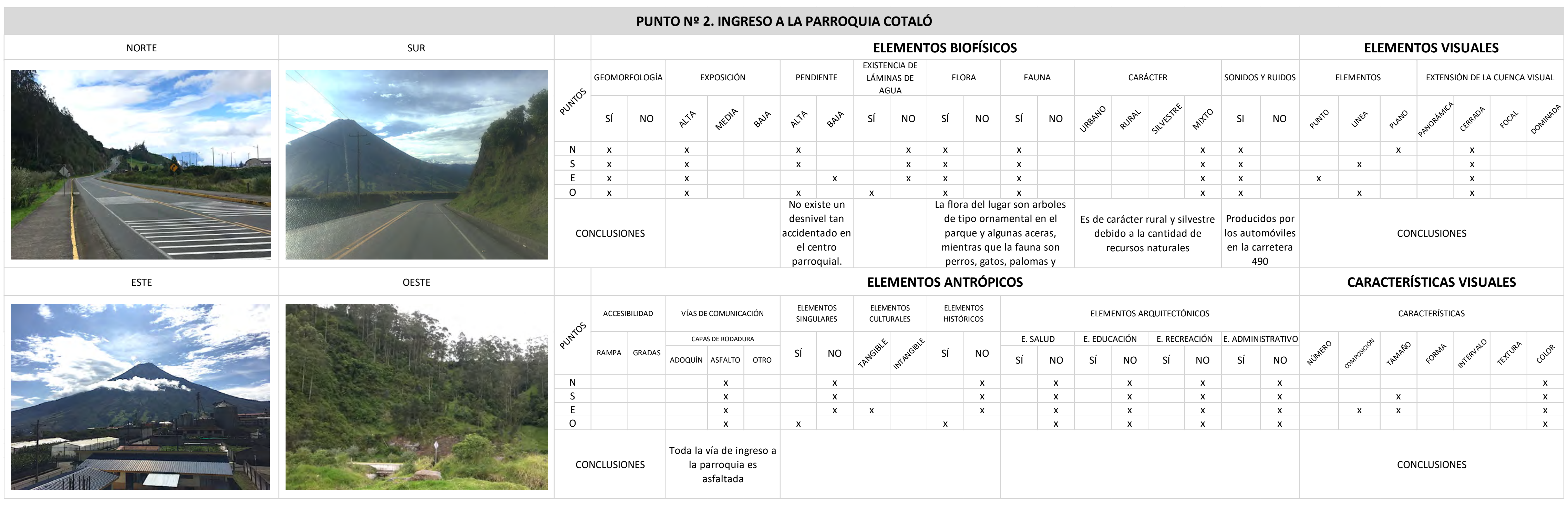

Anexo 2. Punto 2. Ingreso a la parroquia Cotaló.

Nota: Adaptado de Peñaherrera (2020). 


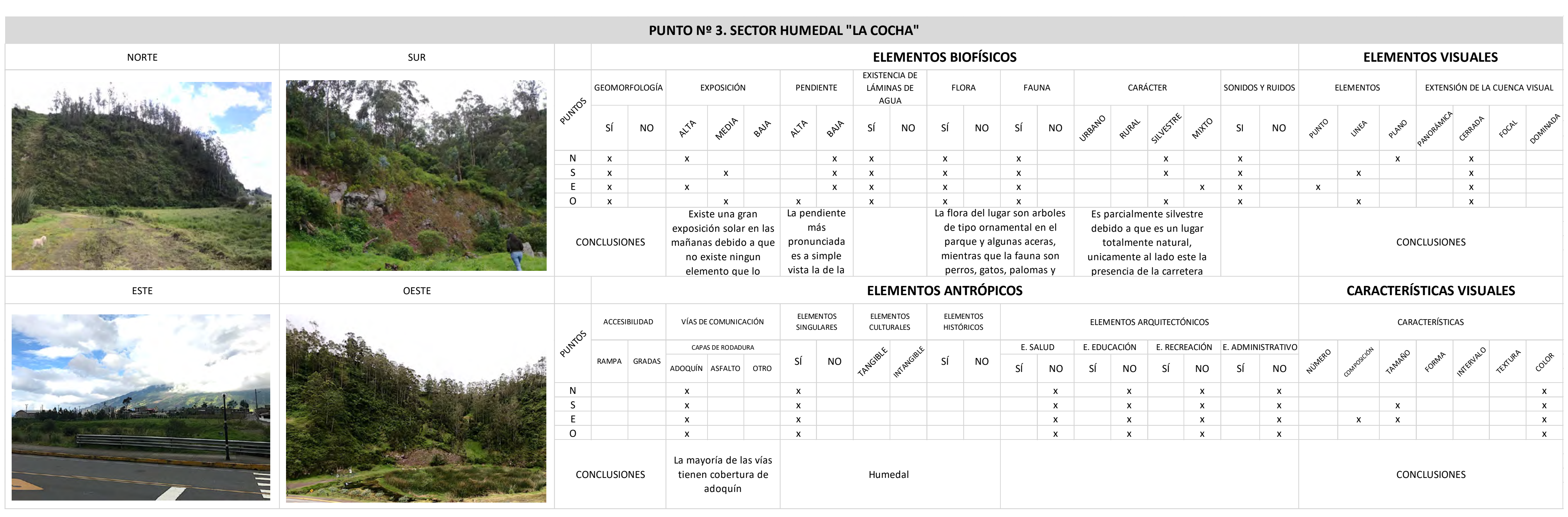

Anexo 3. Punto 3. Sector Humedal "La Cocha".

Nota: Adaptado de Peñaherrera (2020). 


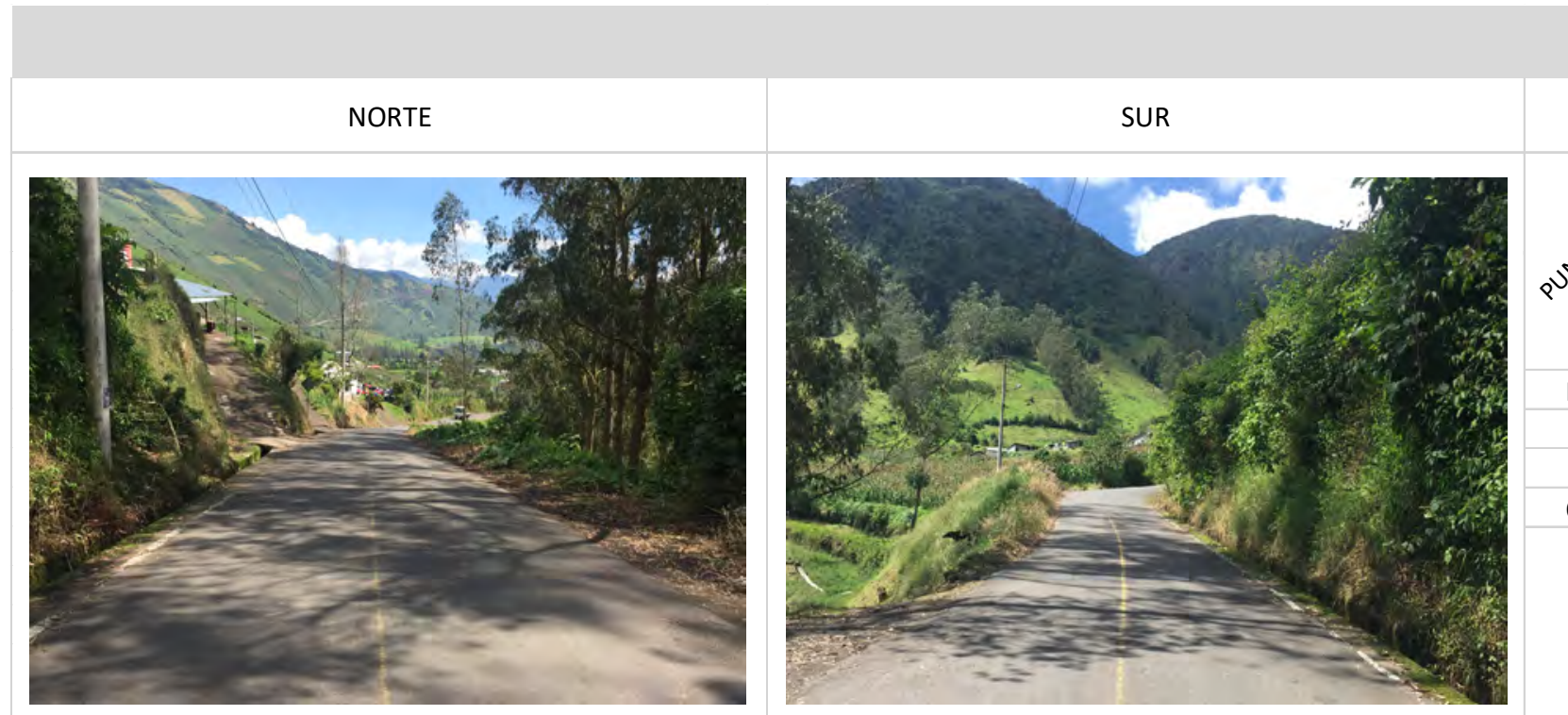

PUNTO № 4. SECTOR VÍA MUCUB

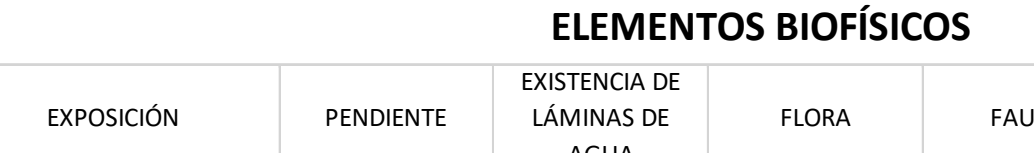

elementos extensión De LA CUenca Visual.

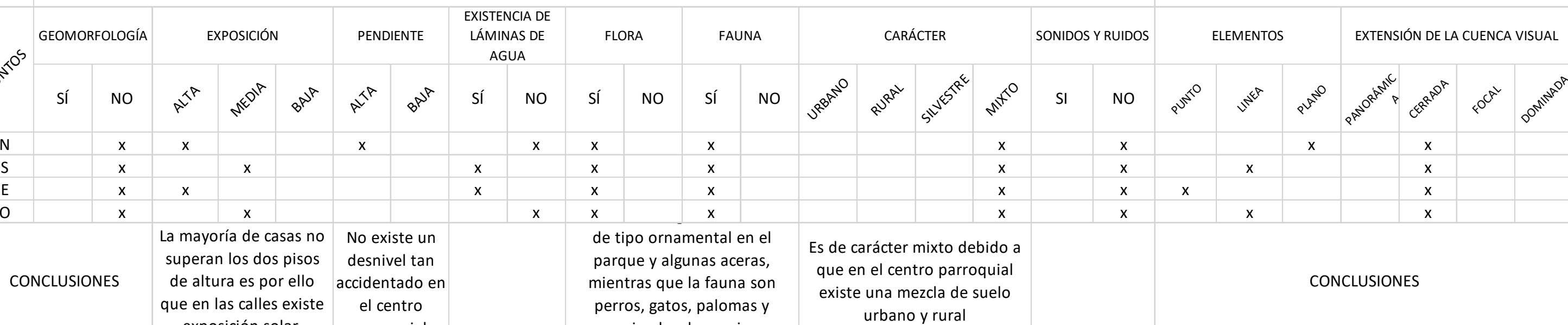

ESTE

OESTE ELEMENTOS ANTRÓPICOS

CARACTERÍSTICAS VISUALES

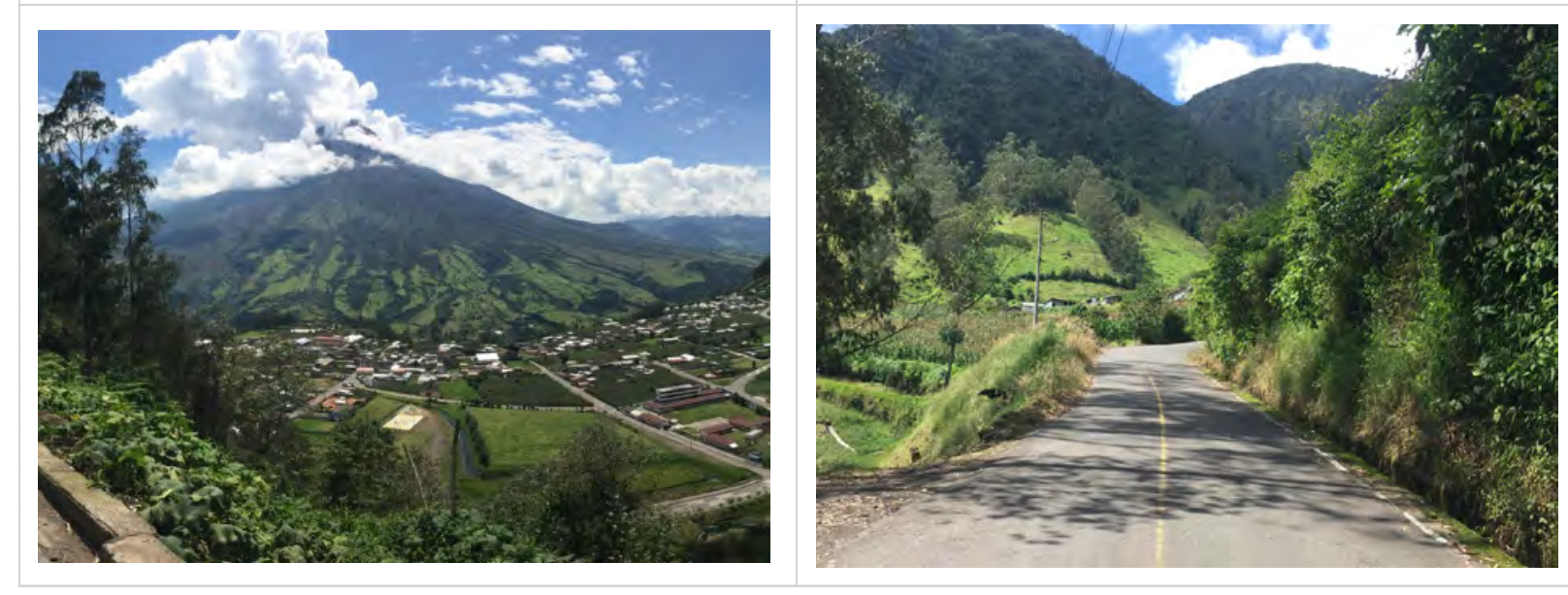

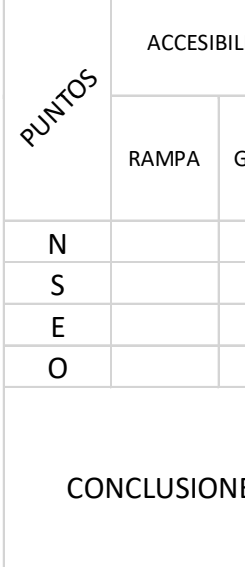

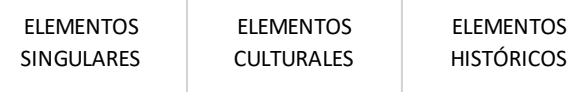

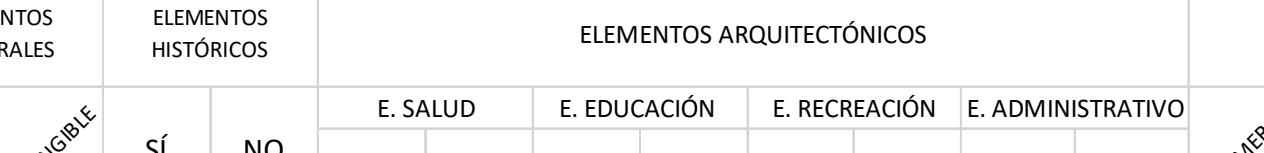

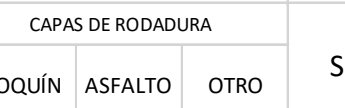

No
$x$
$x$
$x$
$x$

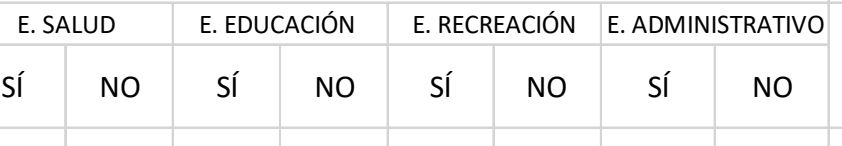

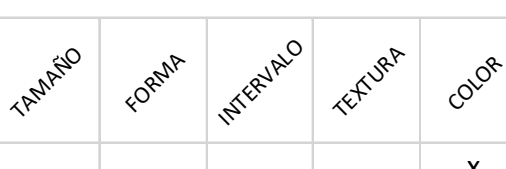

La via a Mucubies
asfatadada

CONCLUSIONES 


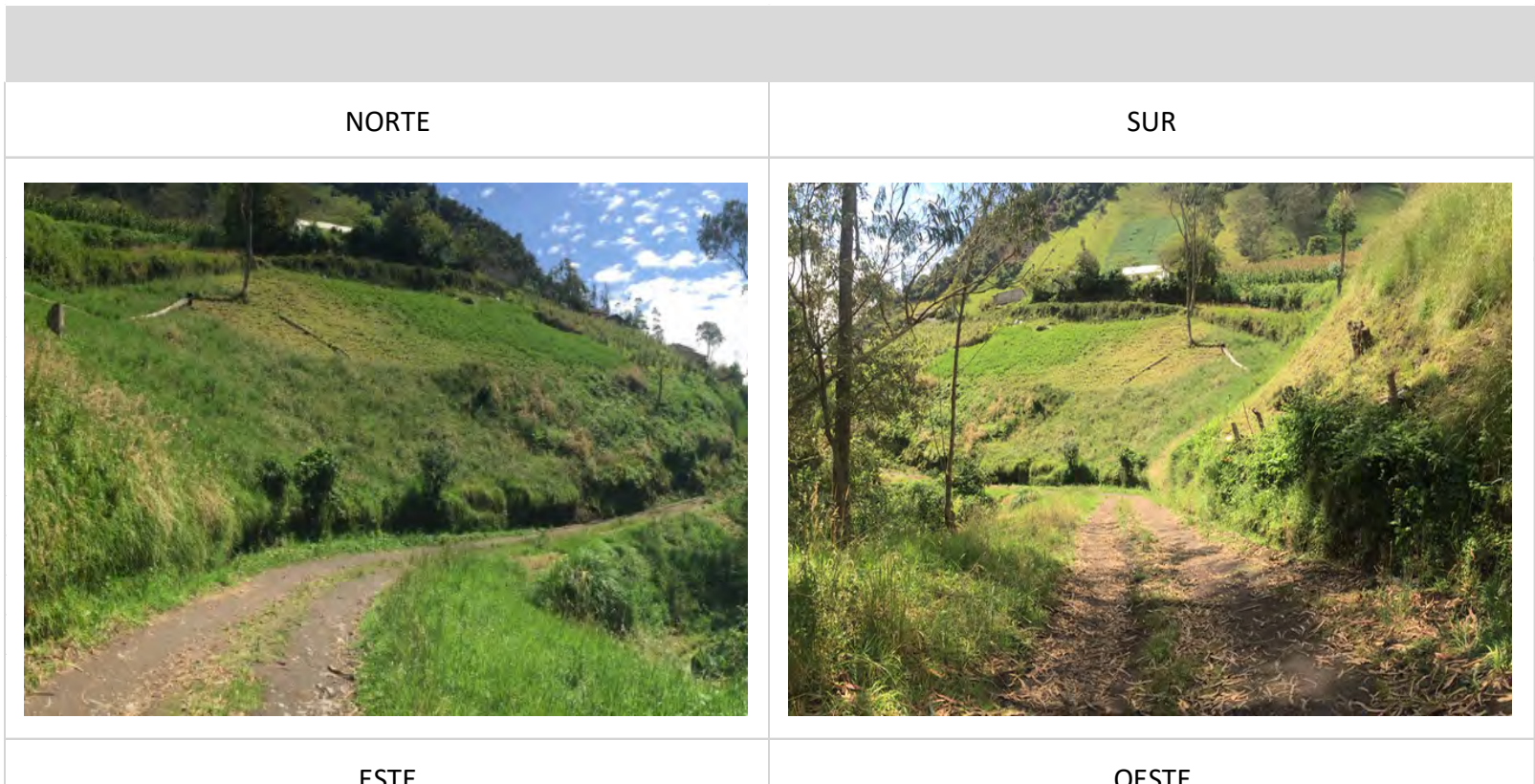

PUNTO № 5 . SENDERO DE MUCUBí ALHUMEDAL" "A COCHA"

ELEMENTOS BIOFÍ́SICOS

EIEMENTOS VISUALES
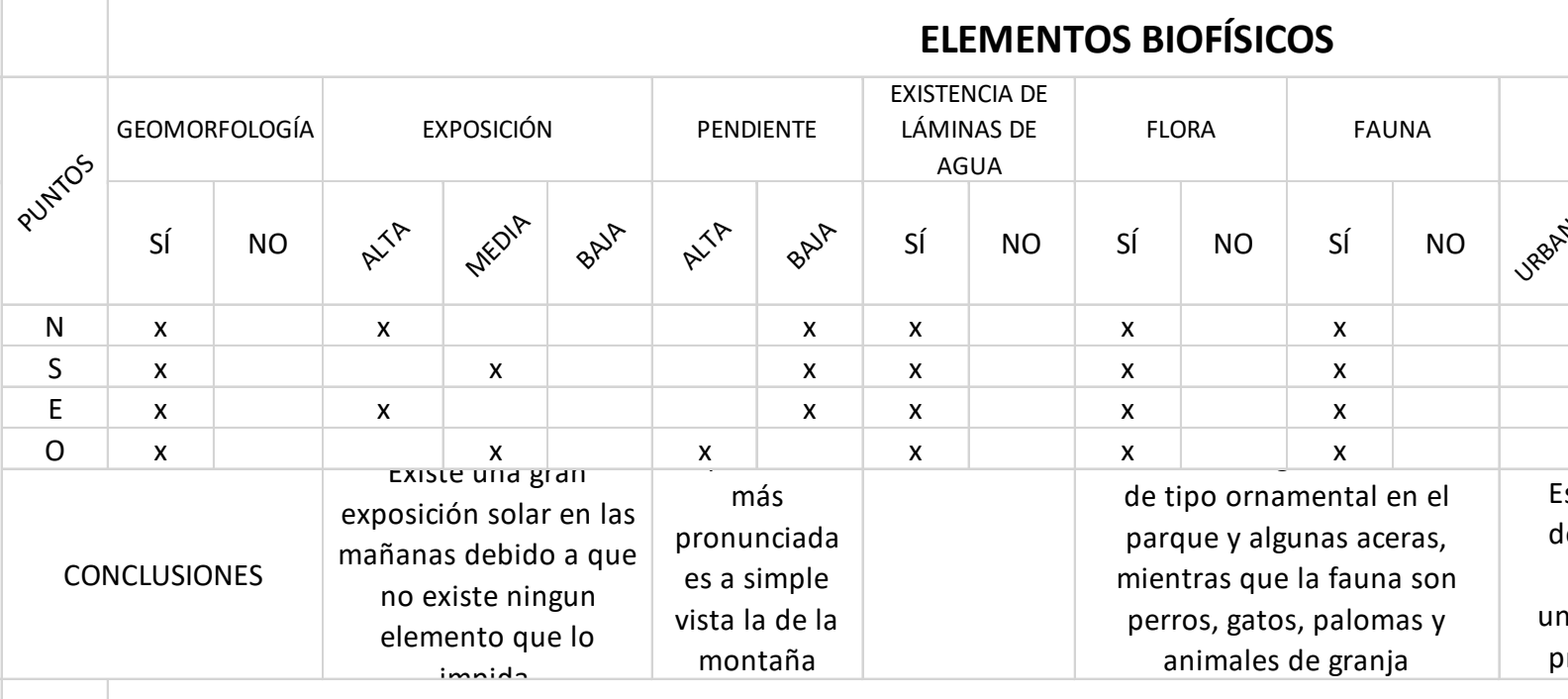

ELEMENTOS ANTRÓPICOS

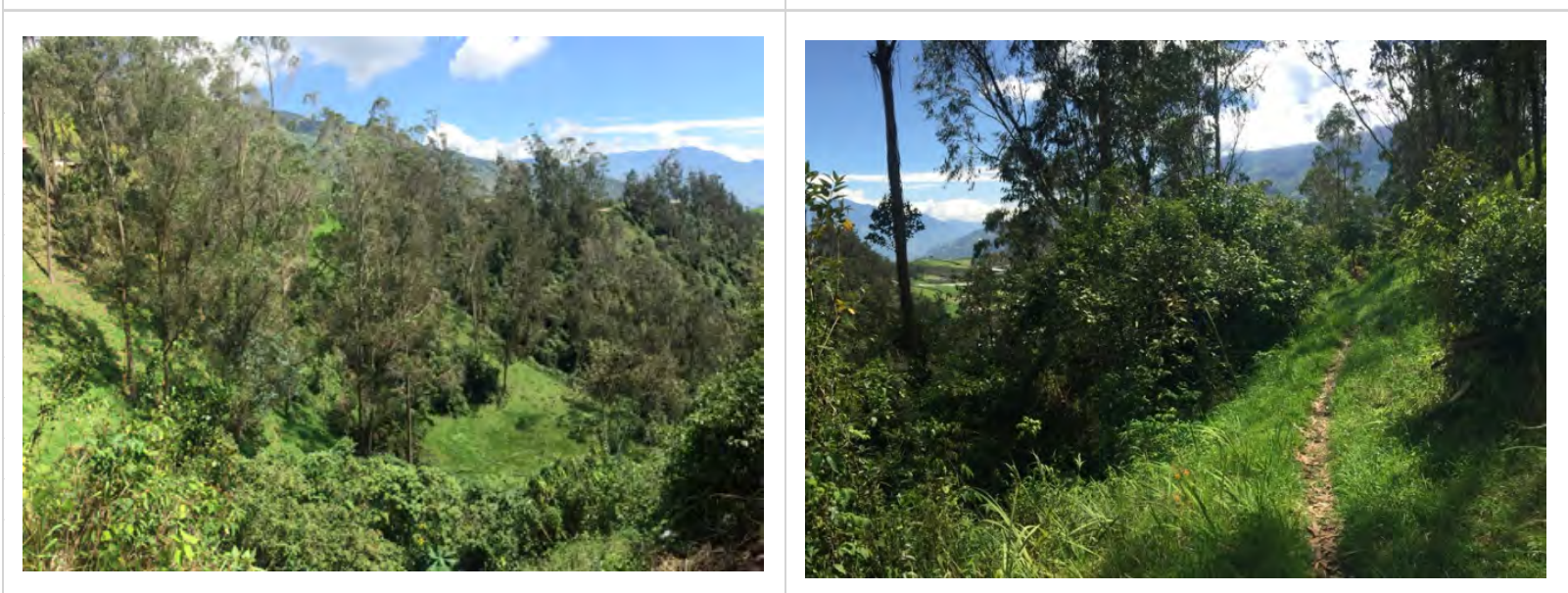

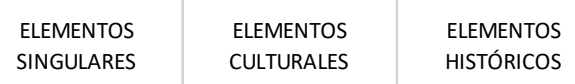

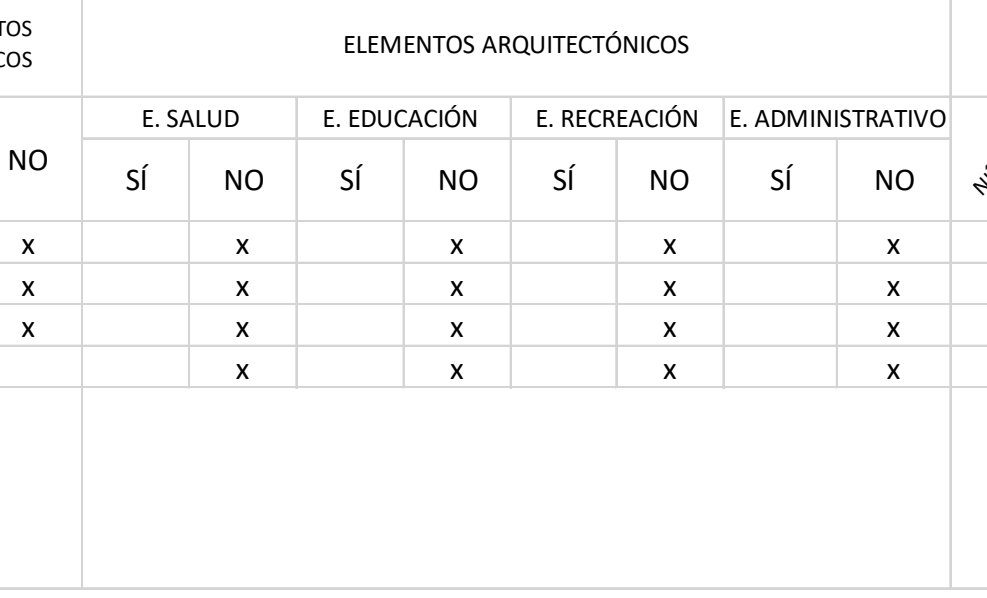

CARACTERISTICAS VISUALES

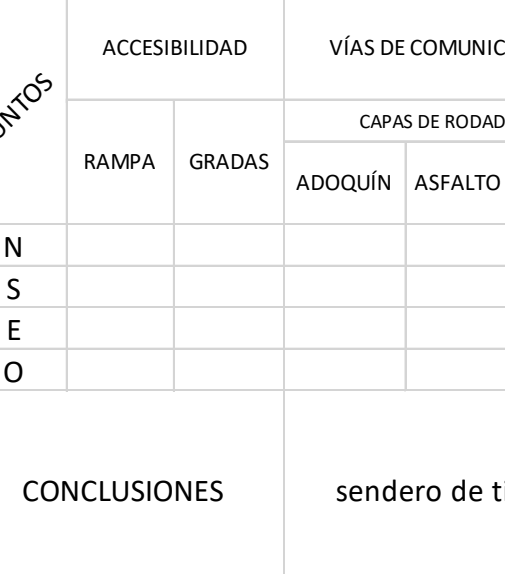

CARACTERSITICAS

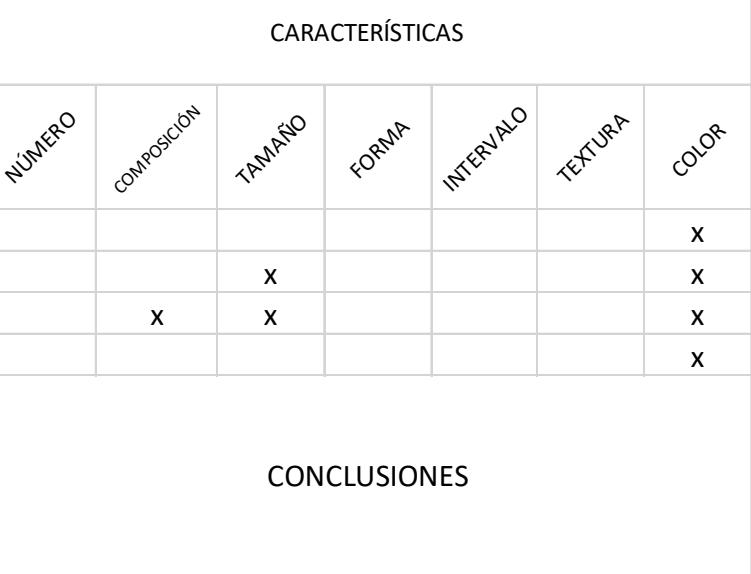

Anexo 5. Punto 5. Sendero de Mucubí a Humedal "La Cocha".

$$
\text { Nota: Adaptado de Peñaherrera (2020). }
$$




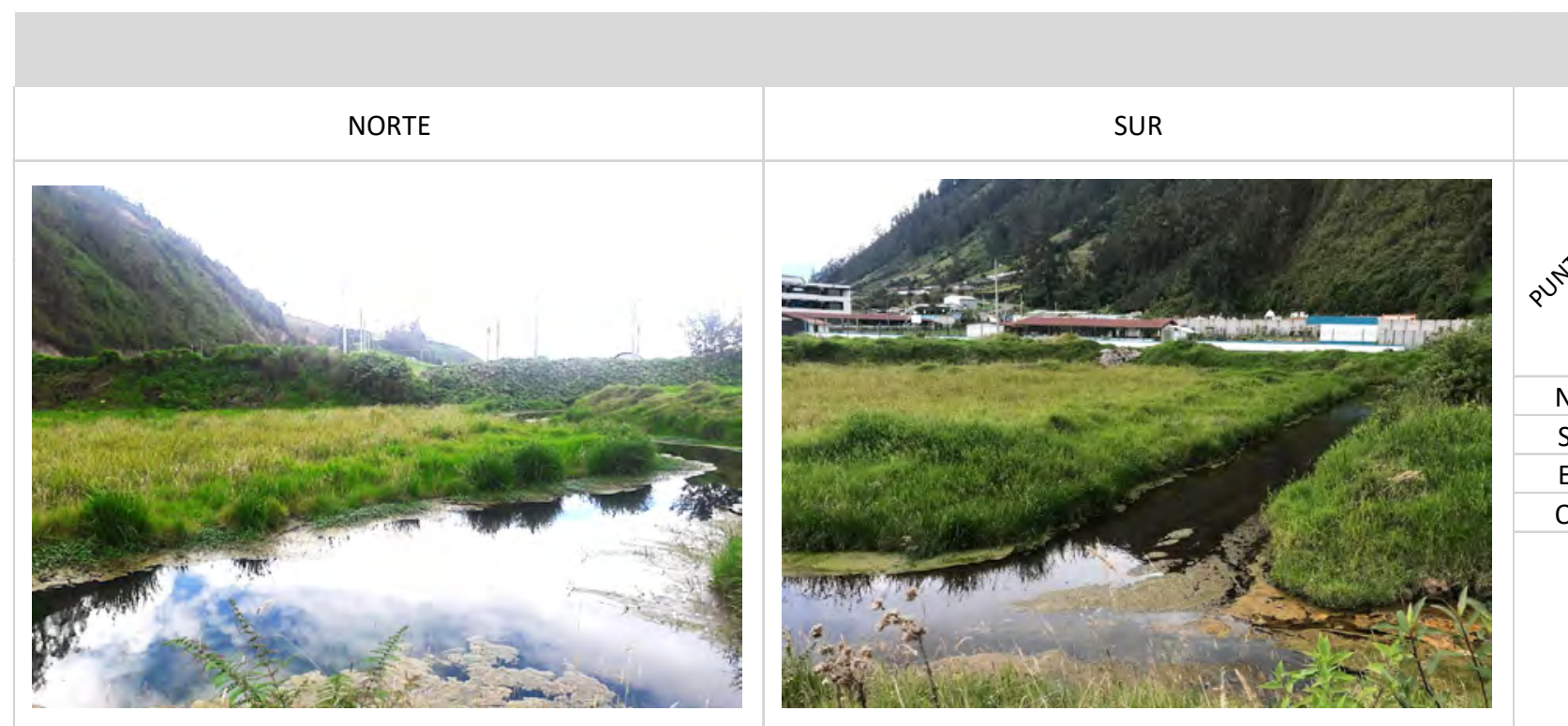

PUNTO № 6. SECTOR SUR CABECERA PARROQUIAL

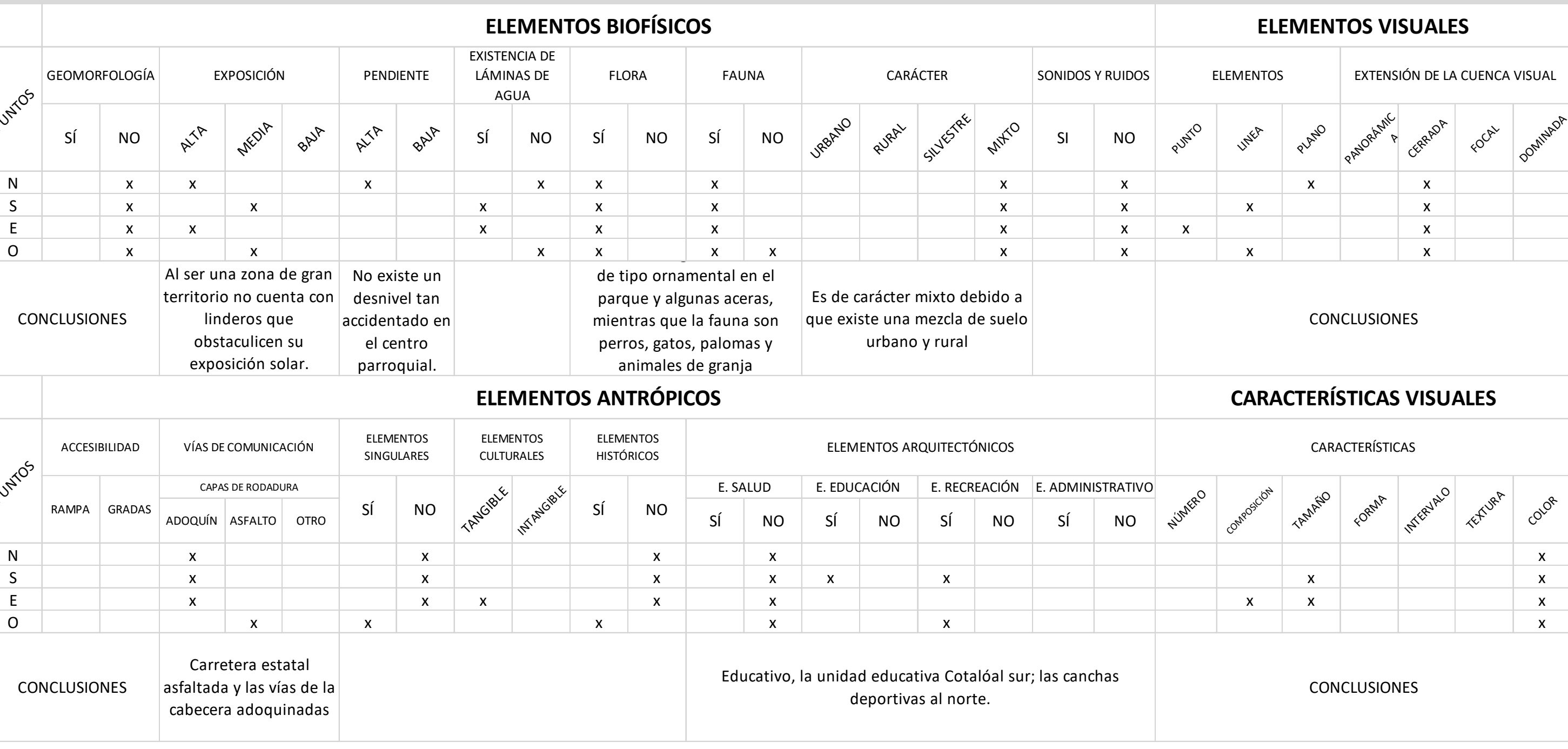

Anexo 6. Punto 6. Sector Sur Cabecera Parroquial.

Nota: Adaptado de Peñaherrera (2020). 


\section{FlORA}

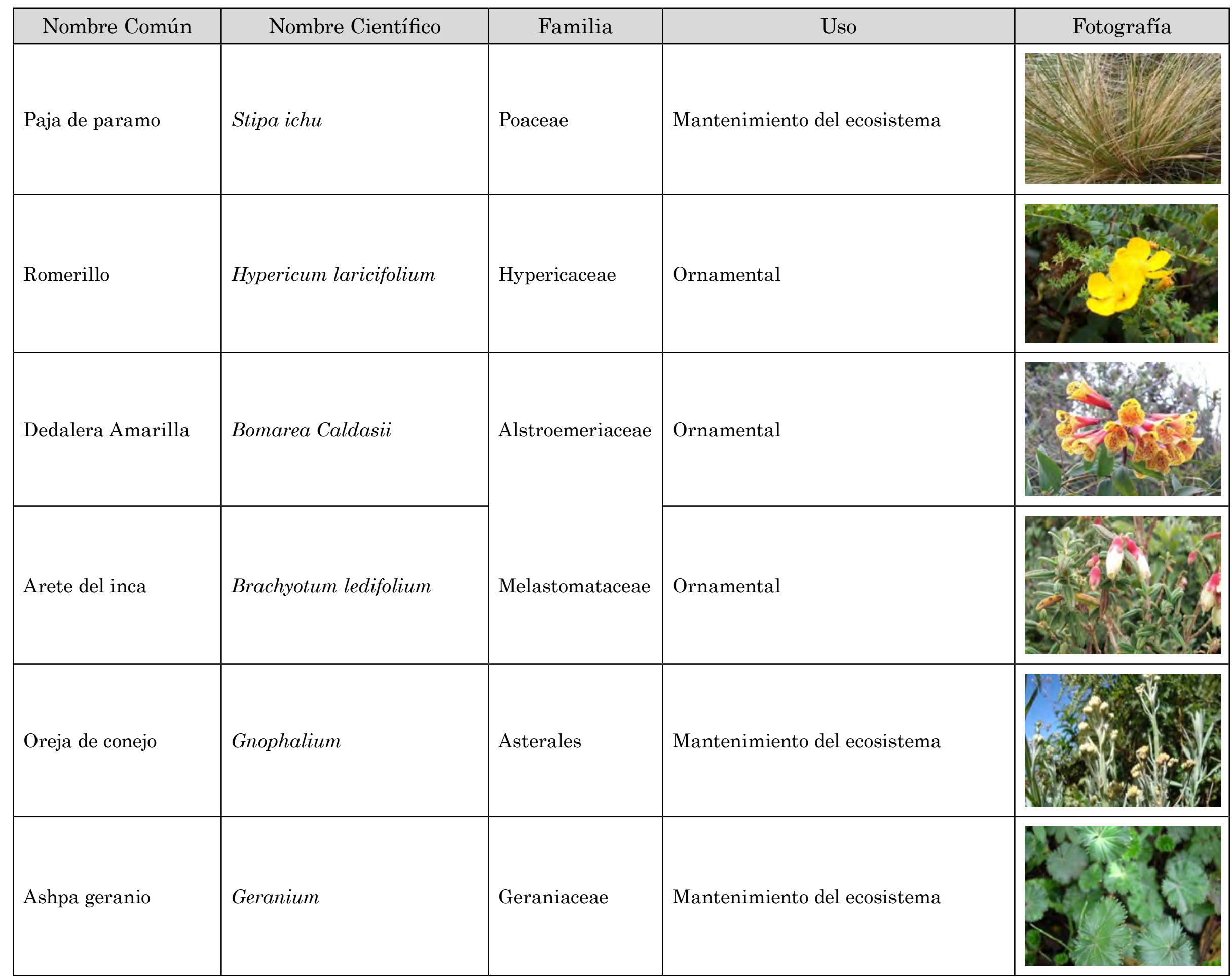




\begin{tabular}{|c|c|c|c|c|}
\hline Nombre Común & Nombre Científico & Familia & Uso & Fotografía \\
\hline Zapatito & Calceolaria & Calceolariaceae & Ornamental & \\
\hline Granizo & Valeriana microphyla & Valerianaceae & Medicinal & \\
\hline Carasquillo & Berberis warszewiczii & Berberidaceae & Mantenimiento del ecosistema & \\
\hline Sigse & Cortaderia nítida & Poaceae & Mantenimiento del ecosistema & \\
\hline Taxo silvestre & Passiflora & Passifloraceae & Mantenimiento del ecosistema & \\
\hline Colca & Miconia & Melastomataceae & Ornamental & \\
\hline
\end{tabular}




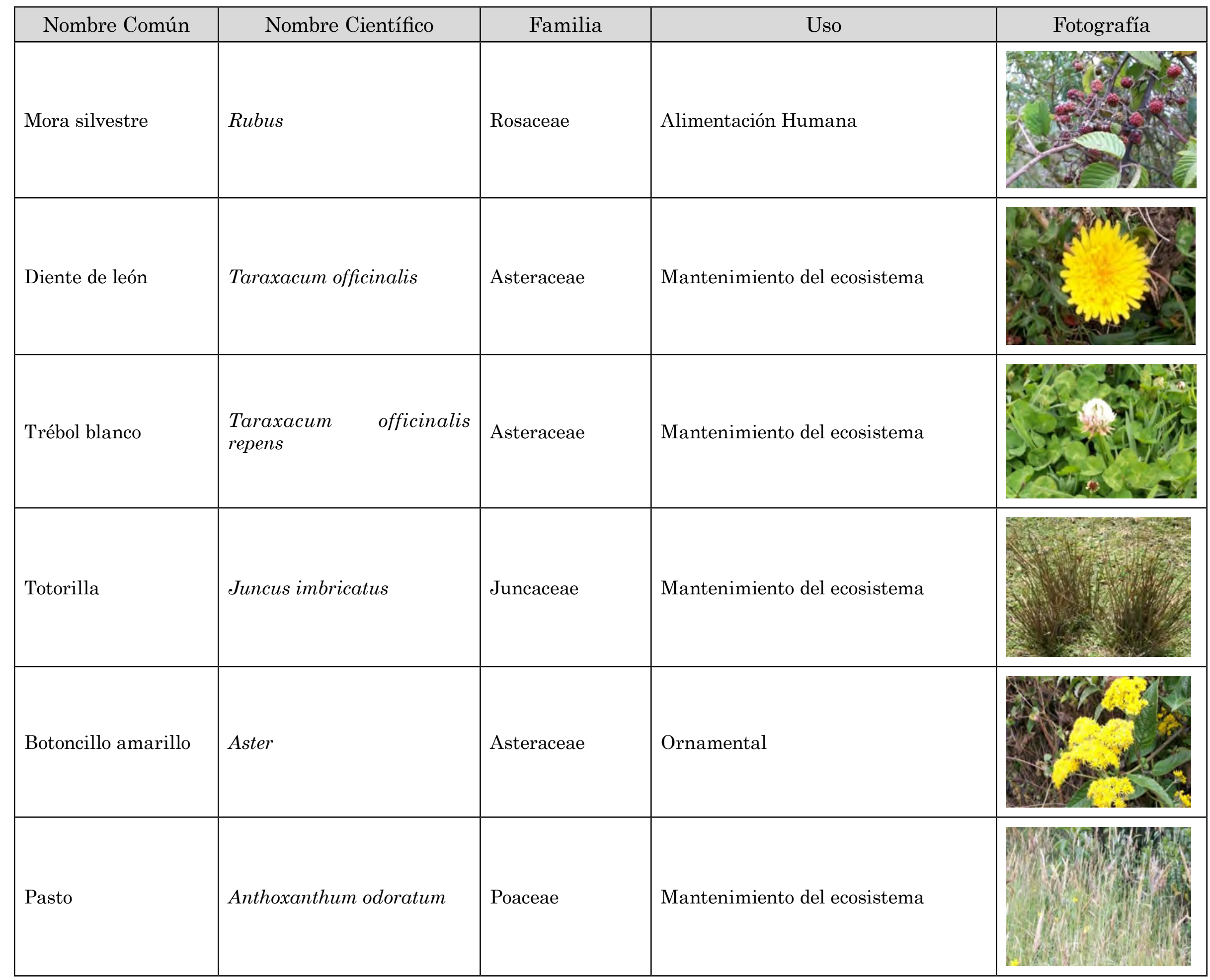


Paisajes rurales: Identificación y caracterización de componentes de paisaje. Parroquia Cotaló. Tungurahua

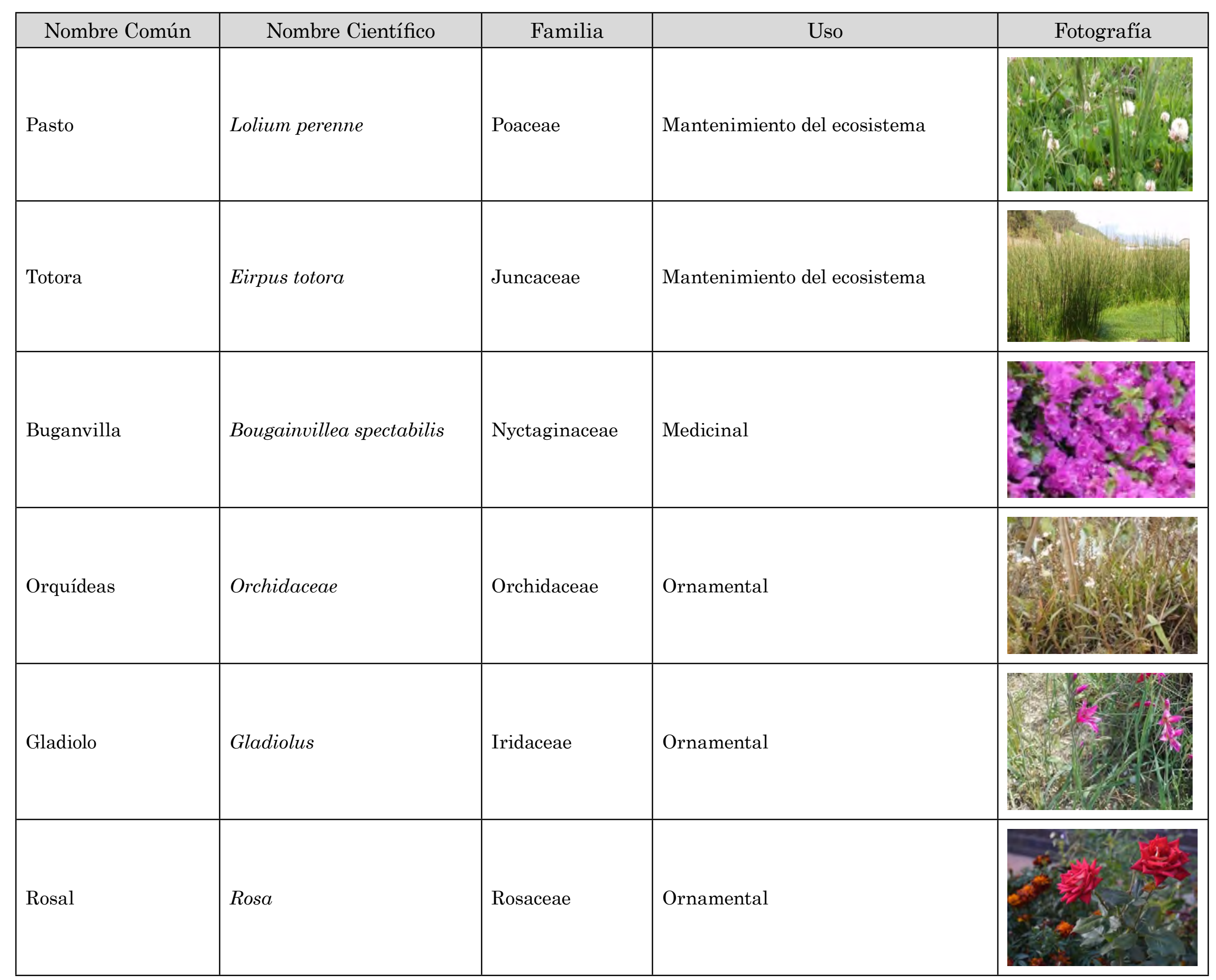

Anexo 7. Flora de la parroquia Cotaló.

Nota. Adaptado de San Pedro de Pelileo (2015). 


\section{Fauna}

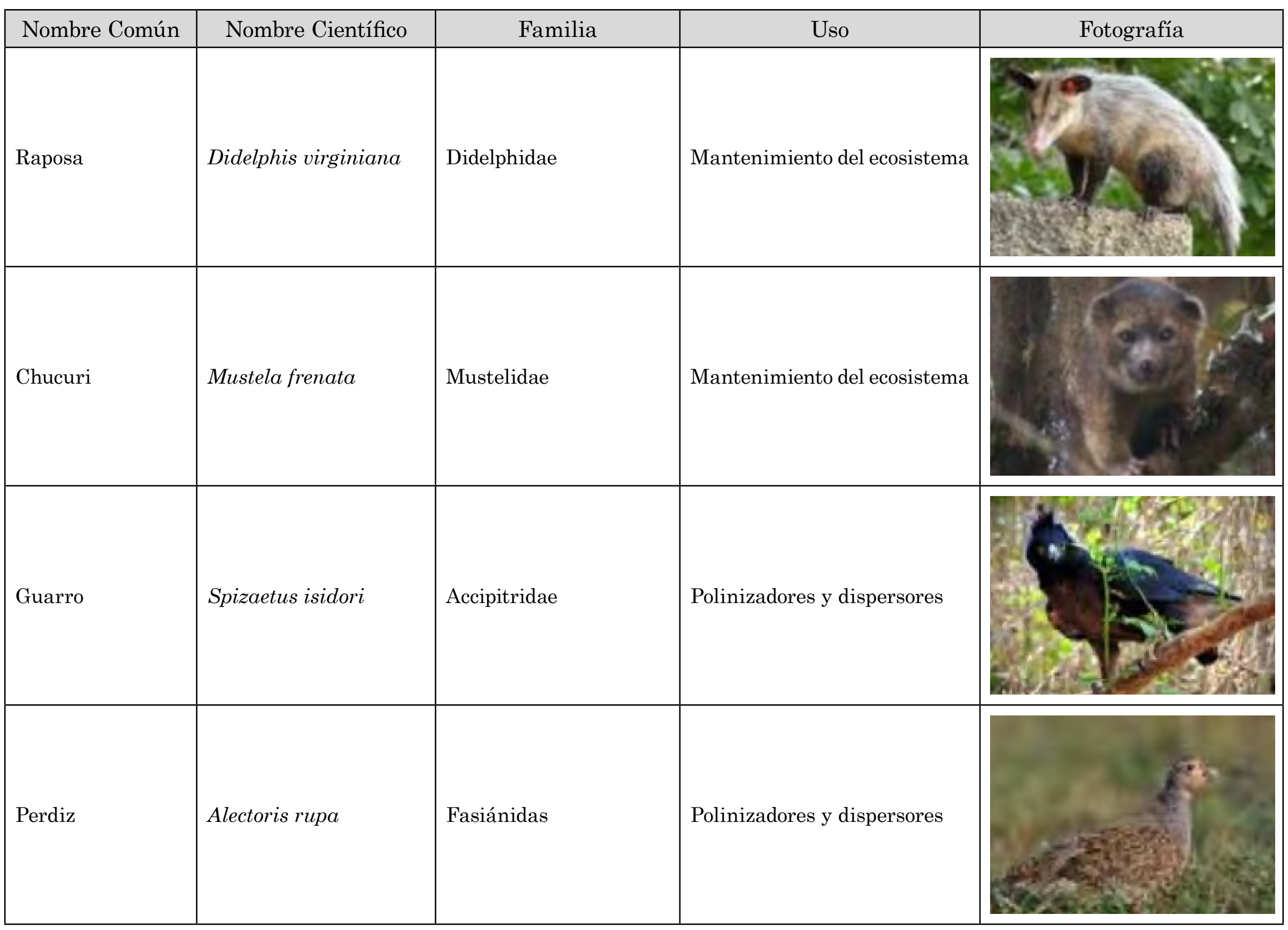


Paisajes rurales: Identificación y caracterización de componentes de paisaje. Parroquia Cotaló. Tungurahua

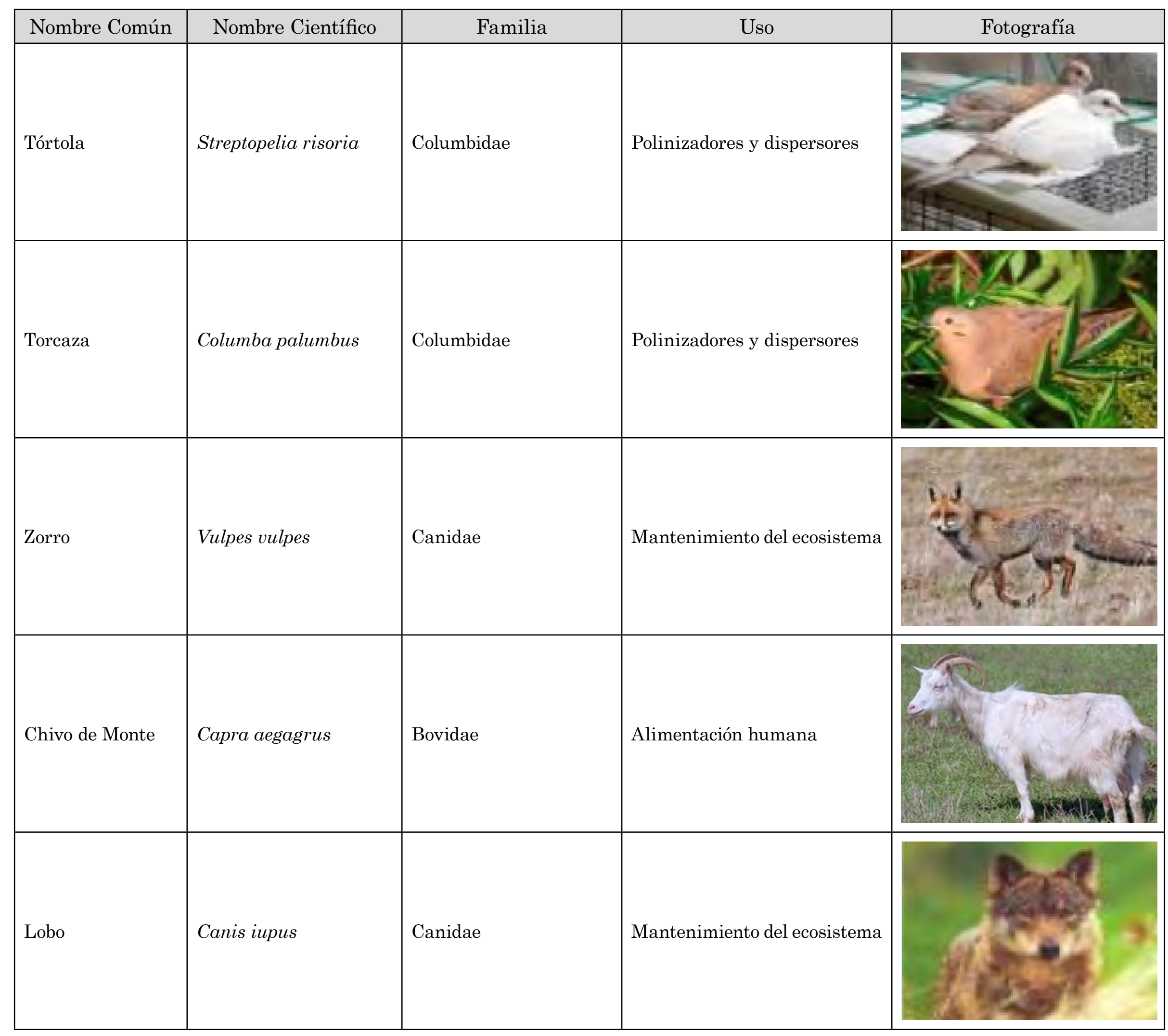




\begin{tabular}{|c|c|c|c|c|}
\hline Nombre Común & Nombre Científico & Familia & Uso & Fotografía \\
\hline Liebre & Oryctolagus cuniculus & Leporidae & Alimentación humana & \\
\hline Pava de monte & Penelope oscura & Cracidae & Alimentación humana & \\
\hline Gavilán & Accipiter nisus & Accipitridae & Polinizadores y dispersores & \\
\hline Búho & Bubo bubo & Strigidae & Polinizadores y dispersores & \\
\hline
\end{tabular}

Anexo 8. Fauna de la parroquia Cotaló.

Nota. Adaptado de Parroquia rural Cotaló (2015) y San Pedro de Pelileo (2015). 